\title{
0 trabalho colaborativo entre 0 atendimento educacional especializado e o ensino regular: um relato de experiência com estudantes público-alvo da educação especial e a atividade de modelagem em cerâmica
}

\begin{abstract}
Resumo:
O presente relato analisa o trabalho colaborativo entre os docentes de estudantes público-alvo da educação especial (EPAEE), tanto do AEE (atendimento educacional especializado), quanto da sala de aula regular. Assim como, reflete sobre o potencial pedagógico da atividade de modelagem em cerâmica no processo educativo dos EPAEE. Para tanto, relata-se e analisa-se uma experiência vivida por professoras e estudantes de uma escola da rede pública de ensino do Estado do Pará, envolvendo as etapas do processo de conhecimento e produção artesanal cerâmica dos quais estudantes e professoras foram protagonistas. $O$ relato resgatou escritos e registros fotográficos da experiência em questão e, na sequência, se procedeu com as respectivas análises. O estudo tem como base teórica autores do âmbito da educação, psicologia e antropologia. E os resultados demonstram que o trabalho colaborativo e as vivências desenvolvidas dentro e fora da escola contribuíram para a inclusão dos estudantes, qualificando o processo educativo por meio das experiências sensoriais e da diversidade sociocultural que o fazer cerâmico propicia.
\end{abstract}

\section{Palavras-chave:}

Trabalho colaborativo. Cerâmica. Atendimento educacional especializado. Ensino regular.

\footnotetext{
1 Doutoranda em Educação pelo Programa de Pós-Graduação em Educação da Universidade Federal do Pará. Professora de Educação Inclusiva da Escola de Aplicação da Universidade Federal do Pará - Universidade Federal do Pará. E-mail: anapaulabarca@ufpa.br. ORCID iD: http://orcid.org/00000002-9332-9547.

2 Mestranda em Diversidade Sociocultural pelo Programa de Pós-Graduação em Diversidade Sociocultural do Museu Paraense Emílio Goeldi. Professora de Geografia da Secretaria Estadual de Educação do Estado do Pará - Museu Paraense Emílio Goeldi. E-mail: marcellerolim@gmail.com. ORCID iD: http://orcid.org/0000-0002-5689-3325.
} 


\title{
Collaborative work between specialized educational services and regular education: an experience report with students target audience of special education and the ceramic modeling activity
}

\begin{abstract}
:
This report discusses the collaborative work between teachers of Target Audience Students of Special Education (EPAEE), both from the AEE (Special Educational Service) and from the regular classroom. As well, it reflects on the pedagogical potential of the ceramic modeling activity in the educational process of the EPAEE. Therefore, we report and analyze an experience lived by teachers and students of a public school in the State of Pará, involving the stages of the process of knowledge and artisanal ceramic production in which students and teachers were protagonists. The report retrieved writings and photographic records of the experience in question and then proceeded with the respective analyses. The study is theoretically based on authors from the fields of education, psychology and anthropology. And the results demonstrate that the collaborative work and the experiences developed inside and outside the school contributed to the inclusion of students, qualifying the educational process through sensory experiences and the sociocultural diversity that ceramic making provides.
\end{abstract}

Keywords:

Collaborative work. Ceramics. Specialized educational assistance. Regular education.

\section{Trabajo colaborativo entre los servicios educativos especializados y la educación regular: un informe de experiencia con el público objetivo de los estudiantes de educación especial y la actividad de modelado cerámico}

\begin{abstract}
Resumen:
Este informe analiza el trabajo colaborativo entre profesores de Estudiantes de Educación Especial del Público Objetivo (EPAEE), tanto del AEE (Asistencia Educativa Especial) como del aula regular. Así como, reflexiona sobre el potencial pedagógico de la actividad de modelado cerámico en el proceso educativo de la EPAEE. Por ello, informamos y analizamos una experiencia vivida por docentes y alumnos de una escuela pública del Estado de Pará, involucrando las etapas del proceso de conocimiento y producción cerámica artesanal en el que estudiantes y docentes fueron protagonistas. El informe recuperó escritos y registros fotográficos de la experiencia en cuestión y luego procedió con los análisis respectivos. El estudio se basa teóricamente en autores de los campos de la educación, la psicología y la antropología. Y los resultados muestran que el trabajo colaborativo y las experiencias desarrolladas dentro y fuera de la escuela contribuyeron a inclusión de los estudiantes, calificando el proceso educativo através de las experiencias sensoriales y la diversidad sociocultural que brinda la cerámica.
\end{abstract}

Palabras clave:

Trabajo colaborativo. Cerámica. Asistencia educativa especializada. Educación regular.

\section{Introdução}

A Política Nacional de Educação Especial na perspectiva da educação inclusiva (BRASIL, 2018) preconiza a inclusão de estudantes público-alvo da educação especial (EPAEE) no sistema regular de ensino, no entanto, para que a inclusão escolar se efetive de fato tornam-se necessárias 
mudanças profundas nas concepções e práticas de todos e todas que compõem a escola. Uma dessas mudanças necessárias diz respeito à relação entre sala regular de ensino e o atendimento educacional especializado.

Segundo a Resolução $\mathrm{n}^{\circ} 4$, de dois de outubro de 2009, que institui as diretrizes operacionais para o atendimento educacional especializado (AEE) na educação básica, cabe ao professor do AEE algumas atribuições, entre elas, destaca-se o inciso VIII do Art. 13: “[...] estabelecer articulação com os professores da sala de aula comum, visando à disponibilização dos serviços, dos recursos pedagógicos e de acessibilidade e das estratégias que promovem a participação dos alunos nas atividades escolares".

Fica evidente que o papel do AEE no processo educativo dos EPAEE não é substitutivo à escolarização, função que cabe ao ensino regular. Todavia, nota-se que, em grande parte das escolas, a função de organizar o meio social educativo dos EPAEE fica a cargo do(a) professor(a) do AEE, contribuindo para que esses estudantes fiquem à margem do processo educativo organizado $\mathrm{e}$ vivenciado por seus pares na escola, resultando em exclusão e segregação.

Entende-se, por "meio social educativo" (VYGOTSKI, 2003), aquilo que é organizado intencionalmente pelo professor a fim de contribuir com a formação dos estudantes, constituindo o terceiro elemento do "processo educativo", outro conceito localizado em Vygotski (2003, p. 79). Segundo o autor, o processo educativo é composto por três elementos trilateralmente ativos, são eles: professor, aluno e o meio existente entre eles. Sob a luz desse teórico, não concebemos que o êxito da educação escolar dependa somente do professor, ou do aluno ou dos elementos do meio; diferente disso, acreditamos que os três, de forma conjunta, constituem esse processo.

Considerando que um dos pilares da inclusão escolar é o diálogo entre a sala regular de ensino e o AEE, o presente relato de experiência tem como objetivo desvelar a potência que o trabalho colaborativo entre os dois âmbitos possui, por meio de uma experiência vivida em uma escola da rede pública do Estado do Pará, localizada na cidade de Belém.

O trabalho colaborativo entre os docentes de EPAEE encontra respaldo na literatura atual (CASAL; FRAGOSO, 2019; MARQUES; DUARTE, 2013), indicando que por meio dessa articulação é possível organizar estratégias, práticas e propostas pedagógicas mais compatíveis com a diversidade humana presente nas salas de aulas da educação básica.

Vygotski (1997) aborda o desenvolvimento das pessoas com desenvolvimento atípico a partir dos pressupostos gerais que orientam a sua concepção de desenvolvimento social da personalidade humana consciente. Para o autor, o que é válido para as relações entre desenvolvimento e educação em qualquer ser humano é igualmente válido para a educação das pessoas, que na educação brasileira são denominadas como público-alvo da educação especial. De acordo com essa perspectiva, não podemos pensar em propostas pedagógicas para as pessoas com desenvolvimento a termo e outro, mais simplificado, para as pessoas com desenvolvimento atípico, sob pena de reduzir a potencialidade de desenvolvimento desses últimos. Diferentemente disso, devemos organizar o meio social educativo de modo a contemplar a diversidade humana.

O "fazer cerâmico" aqui abordado foi uma alternativa encontrada para integrar, além dos estudantes entre si, também os conteúdos trabalhados no ensino regular com uma experiência sensorial que traz no seu "fazer" o conhecimento tradicional dos povos amazônicos do passado.

Entendemos que este "fazer cerâmico" trata também da dimensão da construção de um artefato cerâmico, utilizando técnicas e conhecimentos ancestrais para a elaboração do que chamamos de "cultura material" e que ultrapassa a materialidade, considerando o valor afetivo e as habilidades empregadas pelos estudantes nos objetos em cerâmica construídos na atividade escolar.

Concordamos com Lima (2011) quando ela diz que as coisas materiais mudam porque as pessoas também mudam; os artefatos possuem significados e refletem o comportamento humano. 
Nessa linha de pensamento, a cultura material foi entendida como um reflexo passivo da cultura, sendo esta conceituada como um conjunto de normas, valores, ideias, prescrições e regras formais partilhado por um determinado grupo. Inertes, os artefatos portariam significados que lhes seriam inerentes, cabendo ao investigador tão somente a tarefa de retirar deles a poeira do tempo para que esses significados aparecessem e o passado pudesse ser reconstruído (LIMA, 2011. p. 13).

A cultura material é indissociável e constitutiva da condição humana desde o seu surgimento e, portanto:

[...] é produzida para desempenhar um papel ativo, é usada tanto para afirmar identidades quanto para dissimulá-las, para promover mudança social, marcar diferenças sociais, reforçar a dominação e reafirmar resistências, negociar posições, demarcar fronteiras sociais e assim por diante. Não há como reverter essa condição, que torna a cultura material, de fato, a dimensão concreta das relações sociais. (LIMA, 2011, p. 21-22).

As culturas materiais estão vivas nas relações com a sociedade, com as comunidades, com as instituições, e também com os estudantes envolvidos numa simples atividade colaborativa na escola, desempenhando um importante papel de integração entre a comunidade escolar.

Através da abordagem interdisciplinar e colaborativa que as professoras utilizaram nessas vivências foi possível perceber uma valorização dos EPAEE por parte dos demais estudantes da escola, em que a participação integrada e o trabalho colaborativo de fato contribuíram para uma inclusão efetiva na escola.

A experiência do contato e da modelagem com argila proporcionou aos estudantes uma experiência sensorial, na qual se pôde ativar memórias, distinguir texturas, exercitar sua criatividade, se desafiar e acreditar no seu potencial. O que para os demais estudantes pode ter sido uma atividade manual simples, para os EPAEE, foi um grande desafio a ser cumprido, várias tentativas foram feitas até que cada um, dentro de suas limitações, pôde experimentar e criar suas próprias peças em argila e depois vê-las transformadas em cerâmica.

Portanto, entendemos que "[...] com o mundo em transformação constante e com os avanços que temos conquistado, vozes surgem em diferentes contextos apontando a importância da interdisciplinaridade na educação e de uma visão mais integrada do conhecimento". (CORSO; ROCHA; GARCIA, 2019, p. 52).

A linguagem tátil e sensível do fazer cerâmico possui um imenso arcabouço de conhecimento tradicional que, aliado ao processo educacional, trouxe resultados muito valorosos de experiência sensorial e educativa.

Certas de que: 1) O trabalho colaborativo entre os docentes de EPAEE é um elemento basilar para efetivar inclusão escolar; 2) os EPAEE são integrantes ativos no processo educativo; 3) o trabalho com a modelagem em cerâmica é potente para contribuir com a formação humana dos indivíduos. Convidamos aos(às) leitores(as) a conhecerem uma fecunda experiência que converge com as afirmações supracitadas.

\section{Metodologia}

A parceria de trabalho entre o atendimento educacional especializado e o ensino regular ocorreu na Escola Estadual de Ensino Fundamental e Médio Suboficial Edvaldo Brandão de Jesus, no município de Belém do Pará, nos meses de março a setembro de 2019. A atividade foi fruto do diálogo entre a professora de referência da educação especial e a professora de Geografia e Estudos 
Amazônicos, com o intuito de integrar os saberes e os estudantes para juntos participarem da exposição na Feira de Profissões da escola.

A experiência relatada foi realizada em três etapas, são elas: 1) Visita ao Paracuri -distrito oleiro de Icoaraci/PA; 2) oficina de modelagem em cerâmica, a qual ocorreu em dois momentos; 3) a exposição na Feira das Profissões - atividade organizada pela escola.

Cada etapa teve um objetivo pedagógico e educacional específico, em que os estudantes puderam conhecer o lugar e a história de produção regional de cerâmica, observar as técnicas de manufatura da cerâmica artesanal em Icoaraci/PA, entrar em contato com a argila (matéria prima) e aprender a modelar peças, além de expor seus trabalhos para toda a comunidade escolar.

A proposta dessas atividades foi envolver os estudantes de forma que eles pudessem protagonizar cada etapa proposta: 1) serem os pesquisadores/observadores do saber fazer cerâmico local; 2) aprenderem as técnicas de modelagem da argila;3) exporem os resultados da experiência sensorial a qual foram ativamente participantes. Os estudantes foram capazes de realizar todas as atividades propostas pelas docentes, respeitadas suas especificidades e estimulados seus desafios, em que contribuíram com suas ideias e despertaram sua criatividade.

\section{Visita ao Paracuri}

O Paracuri é um bairro do município de Belém, no distrito de Icoaraci, muito conhecido pela tradicional produção de cerâmica local que possui um estilo próprio, mas que também reproduz muitas peças inspiradas nas cerâmicas arqueológicas das Culturas Marajoara e Tapajônica, tradicionais cerâmicas de povos indígenas amazônicos do passado.

A visita ao Paracuri permitiu que os estudantes e professoras tivessem contato com as pessoas que tradicionalmente desenvolvem essa atividade na região metropolitana de Belém, e, apesar dessa região estar localizada muito próxima da escola, a grande maioria dos estudantes não conhecia o polo oleiro. Ultrapassar os muros da escola e conhecer uma realidade tão próxima dos estudantes despertou um olhar mais atento e curioso dos alunos sobre esse ofício tão antigo e tão importante economicamente para a região.

Nesta etapa, solicitou-se a autorização dos responsáveis para que os estudantes pudessem participar da atividade. Vale destacar que o transporte deles foi feito nos carros particulares das professoras e coordenadoras pedagógicas, uma vez que nem a escola nem a secretaria de educação dispõem do transporte. As professoras também fizeram registros audiovisuais e fotográficos da atividade.

A visita ao distrito oleiro de Icoaraci foi um importante momento de integração entre os estudantes, professores e o corpo técnico da escola envolvidos na atividade. Foi uma etapa em que os estudantes ultrapassaram os muros da escola em busca de novos conhecimentos, através da articulação e parceria entre as professoras do atendimento especializado e do ensino regular. Os estudantes fizeram a observação dos espaços onde ocorrem as etapas do processo de modelagem, secagem e queima da cerâmica, no sentido de compreenderem a relação desses conhecimentos tradicionais com os conteúdos trabalhados em sala de aula.

\section{Oficina de modelagem em cerâmica}

A oficina de modelagem em cerâmica foi realizada nas áreas comuns da escola, ministrada pela professora e ceramista do ensino regular com a colaboração da professora de referência do atendimento educacional especializado. 
Um diálogo sobre a diversidade cultural da região amazônica e sua história de longa duração, permeada de vestígios de povos do passado, foi o pontapé inicial para que as professoras conseguissem integrar os conteúdos trabalhados nas disciplinas Geografia e Estudos Amazônicos (ensino regular) aos saberes tradicionais dos povos da Amazônia através do aprendizado da modelagem da argila, que é a matéria prima da cerâmica. Na ocasião, foram apresentados aos estudantes a matéria prima (argila), os instrumentos/ferramentas (tecnologias) e as técnicas tradicionais de modelagem, seus processos de secagem e queima.

Os estudantes compreenderam que para produzir cerâmica é necessário extrair e tratar a argila. Na ocasião, os conteúdos de Geografia e Estudos Amazônicos foram tratados para o entendimento da composição e distribuição geográfica deste mineral, abundante na região amazônica. Primeiramente, os estudantes aprenderam a fazer o tratamento e a limpeza da argila manualmente, depois foram repassadas as principais técnicas: acordelado, mão livre e placa.

A técnica do acordelado é a mais antiga e muito utilizada por povos indígenas do passado e do presente, consiste na construção de peças a partir de rolinhos de argila, um acima do outro e posteriormente apertados com os dedos para a peça adquirir mais aderência e resistência. A técnica de mão livre é a modelagem que também chamamos de belisco, em que fazemos potes e outros objetos a partir de uma bola de argila no tamanho desejado, escavando ou apertando suas paredes até alcançar a forma desejada. Na técnica de placa, estica-se uma quantidade de argila com um rolo (ou garrafa) e posteriormente se constrói o objeto desejado com cortes e colagem utilizando a própria argila umedecida.

Esta etapa aconteceu nos ambientes disponíveis da escola, utilizando-se as mesas e cadeiras da área aberta de refeitório no primeiro momento e, num segundo momento, após a primeira etapa do processo de secagem das peças (peças em estado de couro), foram feitas as incisões e excisões decorativas. O trabalho decorativo despertou a criatividade dos(as) alunos(as) e foram utilizadas algumas ferramentas básicas disponibilizadas pela professora ceramista, como esteques, esponjas, cuités, pincéis, etc. As professoras fizeram todo o registro audiovisual e fotográfico do processo de modelagem, decoração e secagem das peças. E, como a queima é uma etapa mais delicada e requer um forno especial, e a escola não possui, essa fase foi realizada no Paracuri, na tradicional olaria do senhor João Sarmento, um mestre ceramista de Icoaraci.

\section{A exposição na Feira das Profissões}

A Feira das Profissões é uma atividade desenvolvida anualmente na E.E.E.F e Médio Suboficial Edvaldo Brandão de Jesus, onde os estudantes desenvolvem pesquisas e atividades sobre as diversas profissões, buscando um entendimento das profissões formais e informais, com o objetivo de despertar o interesse do público estudantil pelos estudos e ajudá-los a pensar no futuro. Essa atividade conta com a contribuição dos(as) professores(as) do ensino regular, do atendimento especializado e da coordenação pedagógica, as quais acompanham e orientam as pesquisas dos(as) estudantes com a finalidade de realizar uma grande exposição dos trabalhos desenvolvidos durante o semestre.

Integrar os EPAEE nessas pesquisas e atividades foi um grande desafio que as professoras se propuseram a realizar e, ainda que tenham enfrentado muitas dificuldades, conseguiram ultrapassar as expectativas, integrando o ensino especializado e ensino regular.

A exposição na Feira de Profissões foi a culminância das pesquisas, visitas e oficinas realizadas pelo conjunto de estudantes envolvidos neste relato, em que os alunos expuseram as peças modeladas na oficina e dialogaram com outros colegas sobre o aprendizado adquirido durante as etapas do trabalho. 


\section{Análise e discussão}

A partir da experiência relatada, foi possível fazer algumas análises, as quais foram agrupadas em duas categorias, são elas: 1) $\mathrm{O}$ trabalho colaborativo entre AEE e ensino regular; e 2) A modelagem em cerâmica e os EPAEE.

\section{O trabalho colaborativo entre AEE e ensino regular}

Parte considerável da formação inicial docente da educação básica brasileira não contempla os desafios impostos para a efetiva inclusão dos estudantes público-alvo da educação especial. Agravando o quadro, a formação continuada muitas vezes é inexistente, como aponta o censo escolar INEP/MEC (2017), que indica que 94,6\% dos professores da educação básica não possuem cursos destinados à formação continuada em educação especial, torna-se mais preocupante quando se verifica que entre, os professores que atuam no $\mathrm{AEE}$, apenas $43,5 \%$ possuem algum curso orientado para a formação específica em educação especial.

Frente a esses dados, através da experiência relatada aqui, podemos confirmar que houve uma interação entre a educação especial e o ensino regular e que foram favoráveis à criação de uma cultura inclusiva dentro da escola, contribuindo com o rompimento de barreiras que impedem a plena participação dos EPAEE nas vivências escolares. Experiências como essas possibilitam o diálogo e a escuta entre os dois âmbitos, oportunizando que os(as) docentes possam conhecer os limites, as dificuldades e as possibilidades de cada um, favorecendo a colaboração entre eles.

Este pode ser o pontapé inicial para que os(as) docentes, unidos, a fim de oferecer uma educação de qualidade a todos(as) estudantes, resistam e lutem por políticas públicas que garantam formação continuada compatível com as demandas de uma escola inclusiva.

\section{A modelagem em cerâmica e os EPAEE}

As vivências relatadas nas três etapas da referida experiência possibilitaram uma aproximação dos participantes com o saber fazer cerâmico, despertando o interesse e a valorização dos estudantes pelo processo de produção artesanal local. Apesar do distrito oleiro ser próximo ao bairro de moradia e da escola dos educandos, muitos não conheciam a atividade.

Notou-se que alguns estudantes se destacaram com suas produções em cerâmica e, a partir disso, ganharam visibilidade positiva entre os colegas em virtude das habilidades manuais. Esse reconhecimento foi muito significativo para eles, pois por diversas vezes foram vistos como incapazes de ler, escrever ou calcular. A partir dessa atividade, puderam demonstrar algumas de suas potencialidades, fato que contribui com a valorização da diversidade humana e suas múltiplas formas de expressão.

Foi possível perceber que estudantes com diagnóstico de deficiência intelectual associados a outros transtornos, como o Transtorno do Déficit de Atenção com Hiperatividade (TDAH), que apresentavam tempo de concentração reduzidos nas tarefas escolares, encontraram na atividade de modelagem em cerâmica uma opção de tarefa prazerosa e compatível com suas especificidades. Além de estimular a atenção e a concentração desses estudantes, a proposta possibilitou a participação desses com seus pares em atividades comuns, sem exclusão, ou diferenciação. 


\section{Considerações finais}

Por meio da experiência relatada, foi possível perceber muitas habilidades nos estudantes, para além daquelas exigidas e supervalorizadas na sala regular de ensino, as quais muitas vezes não são alcançadas pelos EPAEE, resultando no descrédito do potencial desses estudantes por parte da comunidade escolar. Acreditamos que a escola precisa ser um espaço de valorização das diferentes formas de aprender e de se expressar, somente assim teremos uma escola verdadeiramente inclusiva.

A atividade de modelagem em cerâmica despertou a curiosidade dos estudantes, possibilitou o trabalho em grupo e favoreceu o diálogo sobre os diferentes ritmos. Além de possibilitar a superação de medos, o respeito às diferenças, a valorização da diversidade e a construção de conhecimentos. Assim como mostrou às docentes um horizonte de possibilidades de trabalho colaborativo entre a sala regular de ensino e o AEE com os EPAEE junto aos demais estudantes.

Certas de que o lugar dos estudantes com deficiências, transtornos globais do desenvolvimento e altas habilidades/superdotação é na escola regular, convivendo com seus pares, compartilhamos o presente relato de experiência que demonstra uma possibilidade de trabalho colaborativo e inclusivo dentro da escola regular de ensino.

\section{Referências}

BRASIL. Conselho Nacional de Educação. Câmara de Educação Básica. Resolução CNE/CEB nº 4, de 2 de outubro de 2009. Institui diretrizes operacionais para o Atendimento Educacional Especializado na Educação Básica, modalidade educação especial. Diário Oficial da União, Brasília, DF, 5 out. 2009.

BRASIL. Política Nacional de Educação Especial na perspectiva da Educação Inclusiva, 2008. Disponível em: http:// portal.mec.gov.br/arquivos/pdf/politicaeducespecial.pdf. Acesso em: 13 maio 2021.

CASAL, João Carlos Vieira; FRAGOSO, Francisca Maria Rochas Almas. Trabalho colaborativo entre os professores do ensino regular e da educação especial. Revista Educação Especial. Santa Maria, v. 32, 2019.

CORSO, Josmael; ROCHA, Michel Zózimo da; GARCIA, Rosane Nunes. Um relato de experiência sobre interações entre a Ciência e as Artes Visuais na Educação Básica. Cadernos do Aplicação. Porto Alegre. v. 32, n.1, 2019.

LIMA, Tania Andrade. Cultura material: a dimensão concreta das relações sociais. Boletim do Museu Paraense Emílio Goeldi. Ciências Humanas. Belém, v. 6, n. 1. p. 11-23, jan./abr. 2011.

MARQUES, Aline Nathalia; DUARTE, Márcia. O trabalho colaborativo: uma estratégia de ensino na aprendizagem de alunos com deficiência intelectual. Revista de Ciências Humanas, Frederico Westphalen, v. 14, n. 23, 2013.

VYGOTSKI, Lev Semionovitch. Psicologia Pedagógica. Porto Alegre: Artmed, 2003.

VYGOTSKI, Lev Semionovitch. Obras Escogidas. Tomo V. Fundamentos de defectologia. Madrid: Visor, 1997.

Data de submissão: 15/05/2021

Data de aceite: $27 / 07 / 2021$ 